\section{A nationwide study on prevalence and factors associated with dynapenia in older adults: ELSI-Brazil}

\author{
Estudo nacional sobre prevalência da dinapenia e \\ fatores associados em idosos: ELSI-Brasil \\ Estudio nacional sobre prevalencia de la dinapenia
y factores asociados en ancianos: ELSI-Brasil
}

Viviane Santos Borges 1,2

Maria Fernanda Furtado Lima-Costa 2

Fabiola Bof de Andrade 2

\begin{abstract}
This study aimed to assess the prevalence and factors associated with dynapenia in a nationally representative sample of Brazilians aged 50 years and older. A cross-sectional study was performed with baseline data from the Brazilian Longitudinal Study of Aging (ELSI-Brazil). Dynapenia was defined as low muscle strength (<27kg for men and $<16 \mathrm{~kg}$ for women). Explanatory variables were sociodemographic characteristics, health conditions, health behaviors and physical performance. Analyses were based on multivariate logistic regression and population attributable fractions. Among the 8,396 participants, the prevalence of dynapenia was $17.2 \%$ (16.6\% among men and $17.7 \%$ among women); for those aged 65 years and older, the prevalence was $28.2 \%$ (29.1\% and 27.5\% among men and women, respectively). Dynapenia was positively associated with age, low gait speed, limitations in performing two or more basic daily activities, falls and self-reported chronic diseases; and negatively associated with education level, physical activity and body mass index (overweight/obese, $O R=0.26$ ). Prevalence of dynapenia is high in Brazilian older adults. Educational skills and physical activity improvement present greater potential to reduce dynapenia in this population.
\end{abstract}

Aging; Hand Strength; Physical Functional Performance; Muscle Strength; Socioeconomic Factors

\author{
Correspondence \\ F. B. Andrade \\ Instituto René Rachou, Fundação Oswaldo Cruz. \\ Av. Augusto de Lima 1715, Belo Horizonte, $M G$ \\ 30190-002, Brasil. \\ fabiola.bof@fiocruz.br \\ 1 Universidade de Itaúna, Itaúna, Brasil. \\ 2 Instituto René Rachou, Fundação Oswaldo Cruz, Belo \\ Horizonte, Brasil.
}




\section{Introduction}

Aging is a multifactorial process that causes muscle weakness due to several biological and contextual changes 1,2 . Dynapenia is the age-related loss of muscle strength 3 . When in older adults, it has important implications for the public health system as it increases the risk of falls 4,5 and mortality 6,7 and prolongs hospital stay 8 . Previous studies reported that dynapenia is only partially explained by muscle mass reduction and that other physiologic factors explain muscle weakness in older adults 9,10,11. Loss of muscle strength is more related to impairments in neural (central) activation and/or reductions in skeletal muscle intrinsic force-generating capacity 12,13. Aging reduces the number of motor units and changes their functional properties. Furthermore, significant inequalities have been found regarding this condition 1 , meaning that individuals of lower socioeconomic levels are negatively impacted ${ }^{11}$. Accordingly, the maintenance of muscle strength while aging has high clinical significance 14 because dynapenia is associated with disability 10,15 and chronic diseases 16 , independent of muscle mass.

Regarding dynapenia distribution in the population, literature shows that its prevalence varies depending on setting, definition used and individuals' characteristics, such as health conditions, ranging from $17.8 \%$ in the European population aged 70 and older 16 , to $71.2 \%$ in a fracture clinic in Colombia 17. Most studies on dynapenia have been conducted in developed countries, lacking studies regarding its prevalence and correlates in developing countries 10,11,16.

The heterogeneity in methodological aspects and the few population-based studies with older adults limit evidence in developing countries. Furthermore, according to a literature search, no study has estimated the population attributable fractions (PAFs) to provide a projected proportion of dynapenia in the population. Acknowledging factors associated with this condition and the proportion of the disease that is attributable to each factor is of public health interest, as many of the already known risk factors are modifiable.

In Brazil, the fifth most populous country in the world with approximately $14 \%$ of its population aged 60 years or older 18, few studies have explored dynapenia among older adults. Of the performed studies, one investigated dynapenia in the context of sarcopenia, examining prevalence and factors associated with this latter condition in older residents living in the largest metropolis of the country 19; whereas another investigated whether dynapenia combined with abdominal obesity would increase mortality risk among English and Brazilian older adults 7 . To overcome these gaps, this study was conducted to estimate the prevalence of dynapenia and evaluate its association with socioeconomic, clinical and behavioral factors among community-dwelling Brazilians aged 50 years and older.

\section{Methods}

This was a cross-sectional study with data from the Brazilian Longitudinal Study of Aging (ELSI-Brazil), conducted from 2015 to 2016. Study cohort was a nationally-representative population-based of non-institutionalized community-dwelling Brazilians aged 50 years and older from 70 municipalities of the five major geographic regions of the country. The study used a probabilistic complex sample clustered in four strata, according to population size. In the first three strata, that included municipalities up to 750,000 inhabitants, sample was selected in three consecutive stages: municipalities, census tracts and households. In the fourth strata, with larger municipalities (> 750,000 inhabitants), the sample was selected in two stages: census tract and households. Considering all households, individuals aged 50 and older were invited to participate. Further details on sample design and methodology have been previously described 20.

ELSI-Brazil was approved by the Ethics Committee of the institution (protocol $\mathrm{n}$. 34649814.3.0000.5091). All participants signed consent forms for interviews and physical measurements. This study used data from 8,396 individuals aged 50 years or older consisting on full data on handgrip strength and other study covariates. 


\section{Dependent variable}

Dynapenia was defined through handgrip strength (i.e., maximal voluntary force) ${ }^{3}$. It was measured with a hydraulic hand dynamometer, to assess isometric strength (SAEHAN Corp., South Korea; Model SH5001). Cut-off values for dynapenia were $<27 \mathrm{~kg}$ for men and $<16 \mathrm{~kg}$ for women 21,22 . In a sitting position, participants were instructed to squeeze the device with the dominant hand as hard as they could for two seconds. They were instructed to grasp the dynamometer in the hand and to keep their arms tight to the body with their dominant elbow forming a $90^{\circ}$ angle. A familiarization test was first performed using non-dominant hand 10,23. Then, the test was performed three times with the dominant limb, with a one-minute rest in between. The higher value of the three trials was used as score.

\section{Covariates}

The following independent variables were included: sociodemographic characteristics [age (50-59 years, 60-69 years, 70+ years), gender, marital status (married or in a stable relationship) and education level (0-3 years, 4-7 years, 8+ years)]; health conditions [multimorbidity (yes, no), self-reported depression and limitations in basic activities of daily living (BADL) (yes, no); health-related behaviors [smoking (non-smoker, former smoker or current smoker), physically active (yes, no)] and social participation (yes, no).

Multimorbidity was defined as the presence of two or more chronic diseases (versus one or none) 24 . The number of chronic diseases was defined through a history of medical diagnosis of the following diseases: hypertension, diabetes, chronic obstructive pulmonary disease, osteoarthritis, stroke, asthma, cancer, renal disease or heart disease. BADL limitation was considered difficulty in at least one of the following activities: walking across a room, dressing, bathing, eating, getting in and out of bed (transferring) and toileting 25. Participants who reported less than 150 minutes of moderate-tovigorous physical activity per week were considered inactive ${ }^{26}$. Physical activity was assessed using the International Physical Activity Questionnaire (IPAQ) 27. Gait speed was assessed through the mean of two attempts to walk a 3 -meter path at usual pace (cut-off of lower speed was $\leq 0.8 \mathrm{~m} / \mathrm{s}$ ) 21,28 . History of falls and hospitalization were considered in the 12 months prior to the interview. Body mass index (BMI) was categorized into three groups according to the World Health Organization (WHO) 29: underweight $\left(\mathrm{BMI}<18.5 \mathrm{~kg} / \mathrm{m}^{2}\right)$, normal weight $\left(\mathrm{BMI} \geq 18.5 \mathrm{~kg} / \mathrm{m}^{2}\right.$ and $\left.<25 \mathrm{~kg} / \mathrm{m}^{2}\right)$ and overweight/ obese $\left(\mathrm{BMI} \geq 25 \mathrm{~kg} / \mathrm{m}^{2}\right)$. Social participation was considered performing at least one social activity during the past twelve months [contact with others (through letters, telephone and Internet, inviting people to visit for meals or leisure etc.), going out with others to public places such as restaurants or movie theaters, participation in organized social activities (clubs, community or religious groups, community center etc.), participation in civil associations (councils, community groups, cooperatives, political parties etc.), playing games with friends (checkers, chess, deck, dominoes, billiards, etc.), practicing a hobby (painting, sculpture, drawing, embroidery, knitting, crocheting, gardening, horticulture etc.), short leisure trip, long leisure trip and volunteer work].

\section{Statistical analysis}

Multivariate logistic regression was used to estimate the association between dynapenia and covariates. Results were presented as odds ratios (OR) with 95\% confidence intervals (95\%CI). PAFs were estimated for important variables to primarily health care prevention, such as educational and physical activity, and calculated based on the results of the multivariate regression model using punaf command in Stata software (https://www.stata.com). PAF was defined as the proportion of disease cases within the population attributable to a certain factor. It can also be defined as the proportion of disease cases within the population that could be prevented as a proportion of total disease burden. All analyses were performed using Stata 14.0. 


\section{Results}

Participants mean age was 62.1 years, $53.3 \%$ were female, $65.1 \%$ had a partner and $32 \%$ had $0-3$ years of education (Table 1). Prevalence of dynapenia was $17.2 \%$ among individuals aged $50+$ years, comprehending $16.6 \%$ among men and $17.7 \%$ among women. In $60+$ individuals prevalence of dynapenia was $23.8 \%$ (men $23.7 \%$, women $23.9 \%$ ), whereas in $65+$, prevalence was $28.2 \%$ (men $29.1 \%$, women 27.5\%). Prevalence of dynapenia stratified by age group and its confidence intervals are shown in Figure 1.

According to bivariate analysis (Table 1), dynapenia was associated with the majority of independent variables. Figure 2 shows the results for the final logistic regression model for factors associated with dynapenia. People in older-age groups are more likely to have dynapenia. Older adults with 4-7 and 8+ years of schooling had lower odds (18\%) of dynapenia when compared to those with 0-3 years of schooling. All variables related to general health conditions were significantly associated to dynapenia. Normal weight and overweight/obese were both negatively associated with it $(\mathrm{OR}=0.46$ and $\mathrm{OR}=0.26$, respectively) and physically inactive participants are more likely to present it. PAF values of $10 \%$ (95\%CI: 1.0-18.7) and 16.7\% (95\%CI: 10.0-22.6) were found for low educational level (no education vs. 4-7 years of schooling) and physical inactivity, respectively.

\section{Discussion}

The present study found that almost one fifth of Brazilian older adults were classified as dynapenic: $16.6 \%$ among men and $17.7 \%$ among women. Dynapenia was associated with sociodemographic factors, as well as lifestyle and general health conditions. Among the most important findings are the results regarding PAF, demonstrating that approximately $10 \%$ and $16 \%$ of dynapenia might be attributable to modifiable risk factors such as physical inactivity and lower levels of education, respectively.

Few studies reporting the prevalence of dynapenia and the application of different cut-off points make it difficult to compare studies. Prevalence found in the present study was higher than those observed among individuals aged 60 years and older in São Paulo, Brazil, although this study used lower cut-off points (men $<26 \mathrm{~kg}$; women $<16 \mathrm{~kg}$ ) ${ }^{7}$. Other studies applied higher cut-off points and observed a prevalence of 33.9\% among Mexicans of 50 years and older $(<30$ for men and $<20$ for women) $30 ; 22.5 \%$ among Europeans aged 70 years and older $(<20 \mathrm{~kg}$ for women and $<30 \mathrm{~kg}$ for men) 16 and $44 \%$ in a population of Americans aged 65 years and older 10.

Regarding factors associated with dynapenia, this study results corroborate previous evidence on its positive association with age 1,31,32, as well as its negative association with education level 1,31. Unlike current findings, other authors found that women had higher odds for dynapenia 11,15,17,19.

Age-related increase in prevalence of dynapenia has also been demonstrated in other studies 31,32, including some performed in Brazil 15. Lino et al. 15 found that for every year of age, after 60 years, a mean reduction of $0.11 \mathrm{~kg}$ in grip strength is expected. In an older adults' representative sample in England, it was observed that older individuals had less handgrip strength at baseline and an accelerated loss rate at follow-up 32.

The present findings also confirm the importance of modifiable risk factors for diseases control among older adults 1,11,31,32. Results showed that lower levels of education and physical inactivity increased the odds of having dynapenia and also accounted for $10 \%$ and $16.7 \%$ of their population attributable fractions, respectively. These significant PAF values highlight the need to invest in public policies to tackle these factors throughout life course, as a way to directly and indirectly reduce prevalence of dynapenia. Both conditions are well known common risk factors, associated with other covariates found to be dynapenia-relatable in this study, such as disability 10,15 and health conditions 16,33. Stringhini et al. 33 , recently highlighted the importance of tackling socioeconomic factors to improve health outcomes, by demonstrating that dynapenia PAFs were similar to those of the six major risk factors for premature mortality reduction, targeted by global health strategies. Other studies corroborate the relationship between dynapenia and socioeconomic status: the Survey of Health, Ageing and Retirement in Europe (SHARE) results, composed by individuals aged 50 years and 
Table 1

Distribution of the sample and bivariate analysis according to independent variables. Brazilian Longitudinal Study of Ageing (ELSI-Brazil), 2015-2016.

\begin{tabular}{|c|c|c|}
\hline Variables & $\begin{array}{c}\text { Total } \\
\%\end{array}$ & $\begin{array}{c}\text { Dynapenia } \\
\%(95 \% \mathrm{Cl})\end{array}$ \\
\hline \multicolumn{3}{|l|}{ Age (years) * } \\
\hline $50-59$ & 48.5 & $10.2(8.6-11.9)$ \\
\hline $60-69$ & 30.3 & $15.3(13.2-17.6)$ \\
\hline $70+$ & 21.2 & $36.0(32.6-39.5)$ \\
\hline \multicolumn{3}{|l|}{ Gender } \\
\hline Women & 53.3 & $17.7(15.7-19.9)$ \\
\hline Men & 46.7 & $16.6(14.5-18.9)$ \\
\hline \multicolumn{3}{|l|}{ Schooling (years) * } \\
\hline $0-3$ & 32.0 & $23.6(20.7-26.8)$ \\
\hline $4-7$ & 31.6 & $16.0(14.1-18.2)$ \\
\hline $8+$ & 36.4 & $12.5(10.7-14.5)$ \\
\hline \multicolumn{3}{|l|}{ Marital status * } \\
\hline Married/Partner & 65.1 & $15.3(13.6-17.2)$ \\
\hline Single (without relationship) & 34.9 & $20.6(18.5-23.0)$ \\
\hline \multicolumn{3}{|l|}{ Smoking } \\
\hline Non-smoker & 45.4 & $17.1(14.9-19.5)$ \\
\hline Former smoker & 37.5 & $18.0(16.0-20.3)$ \\
\hline Current smoker & 17.1 & $15.6(13.1-18.3)$ \\
\hline \multicolumn{3}{|c|}{ Physical activity (moderate and/or vigorous) * } \\
\hline Active & 44.3 & $12.7(11.0-14.6)$ \\
\hline Inactive & 55.7 & $20.7(18.7-23.0)$ \\
\hline \multicolumn{3}{|l|}{ Body mass index * } \\
\hline Underweight & 2.0 & $41.8(32.5-51.7)$ \\
\hline Normal weight & 28.5 & $22.2(19.6-25.1)$ \\
\hline Overweight/Obese & 69.5 & $14.4(12.8-16.2)$ \\
\hline \multicolumn{3}{|l|}{ Multimorbidity * } \\
\hline No & 64.6 & $14.3(12.6-16.3)$ \\
\hline Yes & 35.4 & $22.4(20.1-24.8)$ \\
\hline \multicolumn{3}{|l|}{ Falls (previous 12 months) * } \\
\hline No & 78.7 & $15.1(13.4-16.9)$ \\
\hline Yes & 21.3 & $24.9(22.2-27.8)$ \\
\hline \multicolumn{3}{|l|}{ Depression (self-reported) * } \\
\hline No & 81.6 & $16.5(14.6-18.6)$ \\
\hline Yes & 18.4 & $20.2(17.7-22.9)$ \\
\hline \multicolumn{3}{|l|}{ Reduced gait speed $(\leq 0.08 \mathrm{~m} / \mathrm{s})$ * } \\
\hline No & 44.2 & $9.2(7.5-11.2)$ \\
\hline Yes & 55.8 & $23.5(21.3-25.8)$ \\
\hline \multicolumn{3}{|c|}{ Hospitalization (previous 12 months) * } \\
\hline No & 90.7 & $16.4(14.7-18.3)$ \\
\hline Yes & 9.3 & $24.6(20.5-29.1)$ \\
\hline \multicolumn{3}{|c|}{ Limitations in performing 2 or more BADL * } \\
\hline No & 86.7 & $14.7(13.1-16.5)$ \\
\hline Yes & 13.3 & $33.0(29.3-37.1)$ \\
\hline \multicolumn{3}{|l|}{ Social activities * } \\
\hline No & 94.3 & $16.7(15.1-18.6)$ \\
\hline Yes & 5.7 & $24.3(19.5-29.8)$ \\
\hline
\end{tabular}

BADL: basic activities of daily living.

$* p<0.001$ 
Figure 1

Prevalence (\%) of dynapenia in Brazilian individuals stratified by age group.

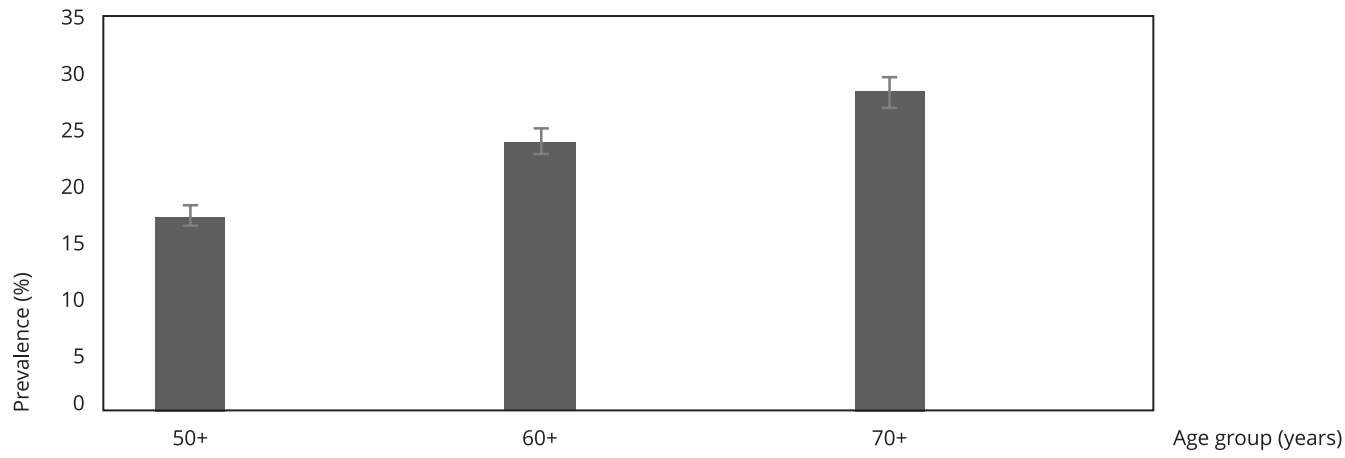

Figure 2

Estimated odds ratios (OR) with 95\% confidence intervals for dynapenia-associated factors. Brazilian Longitudinal Study of Ageing, 2015-2016.

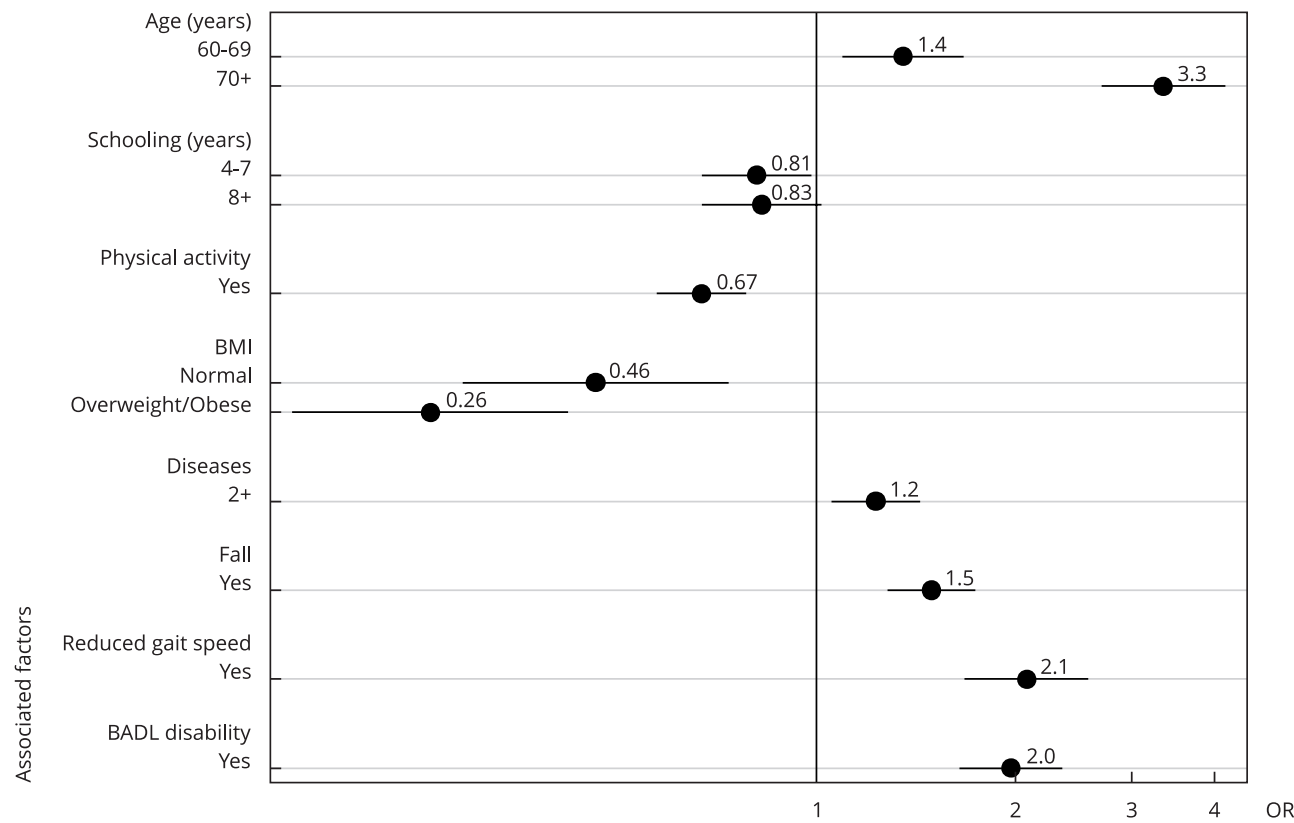

BADL: basic activities of daily living; BMl; body mass index. 
older that live in 14 European countries, found that older adults with early- and adult-life socioeconomic disadvantages and unhealthy lifestyles had a greater risk of low muscle strength 11 .

Regarding lifestyle, physical activity is the first-line proposed intervention to improve functioning and prevent muscle weakness in older adults 14 . Although few studies have specifically evaluated the relationship between clinically defined dynapenia and physical activity among older adults, available evidence demonstrates a positive association between them 14 .

Positive disabilities association and negative mobility association with dynapenia have been previously reported. Duchowny et al. 10 observed that older adults with muscle weakness present a significantly increased risk of experiencing a deterioration in their ability to engage in basic activities of daily living. However, one study found no association between dynapenia and disabilities among Brazilian older adults aged 60 years or older 19 , and similar results were found among older adults attending a falls and fractures clinic ${ }^{17}$. As for mobility, individuals with reduced gait speed had higher odds for dynapenia. Corroborating these findings, previous studies have demonstrated a mean reduction of $2.16 \mathrm{~kg}$ in grip strength of older adults with reduced mobility (Timed Up and Go Test) for every additional second in the mobility test, with a mean decrease of $0.08 \mathrm{~kg}$ in grip strength 15 .

Finally, the relationship between grip strength and obesity has been inconsistently reported. On one hand, positive association has been previously observed, although association pathways were not clearly elucidated 34 . Keevil et al. 34 found that grip strength increases across BMI quartiles and observed a difference of $2.70 \mathrm{~kg}$ between the highest and the lowest BMI quartile in men and $1.46 \mathrm{~kg}$ in women. These authors suggested that BMI represents body size and composition related to lean mass increase and, consequently, grip strength. Furthermore, the study highlighted that the findings are consistent with evidence on a negative impact of undernutrition on health outcomes, as higher BMI relates to lower mortality among older adults. On the other hand, other studies suggested neither positive 35 nor negative association between obesity and hand grip strength 36 .

Among positive aspects of this study, it should be mentioned that it was the first nationally representative study to examine prevalence and factors associated with dynapenia in Brazilians aged 50 years and older. PAFs estimation provided an important population-level measurement that can quantify the preventable fraction of related factors with dynapenia. Limitations are related to the cross-sectional design, which restricts the assessment of causality between associated factors and dynapenia; in addition, physical activities, although based on a validated instrument, used selfreported information regarding time of practice, and may therefore have been subject to recall bias.

\section{Conclusions and implications}

This study demonstrated that dynapenia among Brazilians aged 50 years and older relates to a set of socioeconomic and general health factors. Higher PAF values related to modifiable risk factors associated with lifestyle and education level highlight the opportunity for actions throughout life course, as regular physical activity, for example, can improve mobility, develop strength and prevent muscle loss. In Brazil, the world's fifth most populous nation, these data are relevant because it is one of the countries experiencing rapid demographic aging. Therefore, there is a need to continuously monitor the impact of these factors on prevalence of dynapenia to further evaluate the effect of the health policies directed toward promoting healthy aging. 


\section{Contributors}

All the authors contributed equally in the production of the article.

\section{Additional informations}

ORCID: Viviane Santos Borges (0000-0002-93081502); Maria Fernanda Furtado Lima-Costa (00000002-3474-2980); Fabíola Bof de Andrade (00000002-3467-3989).

\section{Conflict of interest}

The authors declare no conflict of interest.

\section{Acknowledgments}

The ELSI-Brazil baseline study was supported by the Brazilian Ministry of Health (DECIT/SCTIE - Department of Science and Technology from the Secretary of Science, Technology and Strategic Inputs (Grant 404965/2012-1); COSAPI/DAPES/ SAS - Healthcare Coordination of Older Adults, Department of Strategic and Programmatic Actions from the Secretariat of Health Care) (Grants 20836, 22566 and 23700); and the Brazilian Ministry of Science, Technology, Innovation and Communication.

\section{References}

1. Arokiasamy P, Selvamani Y. Age, socioeconomic patterns and regional variations in grip strength among older adults (50+) in India: evidence from WHO's Study on Global Ageing and Adult Health (SAGE). Arch Gerontol Geriatr 2018; 76:100-5.

2. Clark BC, Manini TM. Functional consequences of sarcopenia and dynapenia in the elderly. Curr Opin Clin Nutr Metab Care 2010; 13:271-6.

3. Clark BC, Manini TM. Sarcopenia $\neq$ dynapenia. J Gerontol A Biol Sci Med Sci 2008; 63:829-34

4. Moreland JD, Richardson JA, Goldsmith CH, Clase CM. Muscle weakness and falls in older adults: a systematic review and meta-analysis. J Am Geriatr Soc 2004; 52:1121-9.

5. Scott D, Daly RM, Sanders KM, Ebeling PR. Fall and fracture risk in sarcopenia and dynapenia with and without obesity: the role of lifestyle interventions. Curr Osteoporos Rep 2015; 13:235-44.

6. Newman AB, Kupelian V, Visser M, Simonsick EM, Goodpaster BH, Kritchevsky SB, et al. Strength, but not muscle mass, is associated with mortality in the health, aging and body composition study cohort. J Gerontol A Biol Sci Med Sci 2006; 61:72-7.

7. da Silva Alexandre T, Scholes S, Ferreira Santos JL, de Oliveira Duarte YA, de Oliveira C. Dynapenic abdominal obesity increases mortality risk among English and Brazilian older adults: a 10-year follow-up of the ELSA and SABE studies. J Nutr Health Aging 2018; 22:138-44

7. Rossi AP, Fantin F, Abete P, Bellelli G, Bo M, Cherubini A, et al. Association between hospitalization-related outcomes, dynapenia and body mass index: The Glisten Study. Eur J Clin Nutr 2018; 73:743-50.

9. Manini TM, Clark BC. Dynapenia and aging: an update. J Gerontol A Biol Sci Med Sci 2012; 67:28-40.

10. Duchowny KA, Clarke PJ, Peterson MD. Muscle weakness and physical disability in older Americans: longitudinal findings from the U.S. Health and Retirement Study. J Nutr Health Aging 2018; 22:501-7.

11. Cheval B, Boisgontier MP, Orsholits D, Sieber S, Guessous I, Gabriel R, et al. Association of early- and adult-life socioeconomic circumstances with muscle strength in older age. Age Ageing 2018; 47:398-407.

12. Clark BC, Taylor JL. Age-related changes in motor cortical properties and voluntary activation of skeletal muscle. Curr Aging Sci 2011; 4:192-9.

13. Kostek MC, Delmonico MJ. Age-related changes in adult muscle morphology. Curr Aging Sci 2011; 4:221-33. 
14. Richardson DL, Duncan MJ, Jimenez A, Juris PM, Clarke ND. Effects of movement velocity and training frequency of resistance exercise on functional performance in older adults: a randomised controlled trial. Eur J Sport Sci 2019; 19:234-46.

15. Lino VTS, Rodrigues NCP, O’Dwyer G, Andrade MKN, Mattos IE, Portela MC. Handgrip strength and factors associated in poor elderly assisted at a primary care unit in Rio de Janeiro, Brazil. PLoS One 2016; 11:e0166373.

16. Bertoni M, Maggi S, Manzato E, Veronese N, Weber G. Depressive symptoms and muscle weakness: a two-way relation? Exp Gerontol 2018; 108:87-91.

17. Benjumea A-M, Curcio C-L, Duque G, Gómez F. Dynapenia and sarcopenia as a risk factor for disability in a falls and fractures clinic in older persons. Open Access Maced J Med Sci 2018; 6:344-9.

18. Population Division, Department of Economic and Social Affairs, United Nations. World Population Prospects: the 2015 revision. http:// esa.un.org/unpd/wpp/Publications/Files/ Key_Findings_WPP_2015.pdf (accessed on 20/Dec/2018).

19. da Silva Alexandre T, de Oliveira Duarte YA, Ferreira Santos JL, Wong R, Lebrão ML. Prevalence and associated factors of sarcopenia among elderly in Brazil: findings from the SABE study. J Nutr Health Aging 2014; 18:284-90.

20. Lima-Costa MF, de Andrade FB, Souza PRB, Neri AL, Duarte YAO, Castro-Costa E, et al. The Brazilian Longitudinal Study of Aging (ELSI-Brazil): objectives and design. Am J Epidemiol 2018; 187:1345-53.

21. Cruz-Jentoft AJ, Bahat G, Bauer J, Boirie Y, Bruyère $O$, Cederholm $T$, et al. Sarcopenia: revised European consensus on definition and diagnosis. Age Ageing 2019; 48:16-31.

22. Dodds RM, Syddall HE, Cooper R, Benzeval M, Deary IJ, Dennison EM, et al. Grip strength across the life course: normative data from twelve British studies. PLoS One 2014; 9:e113637.

23. Roberts HC, Denison HJ, Martin HJ, Patel HP, Syddall H, Cooper C, et al. A review of the measurement of grip strength in clinical and epidemiological studies: towards a standardised approach. Age Ageing 2011; 40:423-9.

24. Barnet K, Mercer SW, Norbury M, Watt G, Wyke S, Guthrie B. Epidemiology of multimorbidity and implications for health care, research, and medical education: a cross-sectional study. Lancet 2012; 380:37-43.

25. Katz S, Ford AB, Moskowitz RW, Jackson BA, Jaffe MW. Studies of illness in the aged the index of ADL: a standardized measure of biological and psychosocial function. JAMA 1963; 185:914-9.

26. World Health Organization. Global recommendations on physical activity for health. http://whqlibdoc.who.int/publica tions/2010/9789241599979_eng.pdf (accessed on 16/Dec/2018).
27. Guedes DP, Lopes CC, Guedes JERP. Reproducibility and validity of the International Physical Activity Questionnaire in adolescents. Rev Bras Med Esporte 2005; 11:151-8.

28. Cruz-Jentoft AJ, Baeyens JP, Bauer JM, Boirie Y, Cederholm T, Landi F, et al. Sarcopenia: European consensus on definition and diagnosis. Report of the European Working Group on Sarcopenia in Older People. Age Ageing 2010; 39:412-23.

29. World Health Organization. Fact sheet: obesity and overweight. https://www.who.int/ news-room/fact-sheets/detail/obesity-andoverweight (accessed on 22/Oct/2018).

30. Rodríguez-García WD, García-Castañeda L, Vaquero-Barbosa N, Mendoza-Núñez VM, Orea-Tejeda A, Perkisas S, et al. Prevalence of dynapenia and presarcopenia related to aging in adult community-dwelling Mexicans using two different cut-off points. Eur Geriatr Med 2018; 9:219-25.

31. de Lima TR, Silva DAS, de Castro JAC, Christofaro DGD. Handgrip strength and associated sociodemographic and lifestyle factors: a systematic review of the adult population. J Bodyw Mov Ther 2017; 21:401-13.

32. Syddall HE, Westbury LD, Shaw SC, Dennison EM, Cooper C, Gale CR. Correlates of level and loss of grip strength in later life: findings from the English Longitudinal Study of Ageing and the Hertfordshire Cohort Study. Calcif Tissue Int 2018; 102:53-63.

33. Stringhini S, Carmeli C, Jokela M, Avendaño M, Muennig P, Guida F, et al. Socioeconomic status and the $25 \times 25$ risk factors as determinants of premature mortality: a multicohort study and meta-analysis of 1.7 million men and women. Lancet 2017; 389:1229-37.

34. Keevil VL, Luben R, Dalzell N, Hayat S, Sayer AA, Wareham NJ, et al. Cross-sectional associations between different measures of obesity and muscle strength in men and women in a British cohort study. J Nutr Health Aging 2015; 19:3-11.

35. Rolland Y, Lauwers-Cances V, Pahor M, Fillaux J, Grandjean H, Vellas B. Muscle strength in obese elderly women: effect of recreational physical activity in a cross-sectional study. Am J Clin Nutr 2004; 79:552-7.

36. Stenholm S, Sallinen J, Koster A, Rantanen T, Sainio P, Heliövaara M, et al. Association between obesity history and hand grip strength in older adults: exploring the roles of inflammation and insulin resistance as mediating factors. J Gerontol A Biol Sci Med Sci 2011; 66:341-8. 


\section{Resumo}

O estudo teve como objetivo avaliar a prevalência da dinapenia e fatores associados em uma amostra nacional representativa de indivíduos com 50 anos ou mais no Brasil. Foi realizado um estudo transversal. O presente estudo usou dados da linha de base do Estudo Longitudinal da Saúde dos Idosos Brasileiros (ELSI-Brasil). A variável dependente era dinapenia, definida como baixa força muscular (< $27 \mathrm{~kg}$ para homens e $<16 \mathrm{~kg}$ para mulheres). Foram incluídas como covariáveis no modelo logístico, as características sociodemográficas estado de saúde, comportamentos relacionados à saúde e desempenho físico. Foram calculadas frações atribuíveis populacionais para os fatores que demonstrassem associação significativa com o desfecho. Foram estudados 8.386 participantes com 50 anos ou mais (53,3\% do sexo feminino). A prevalência da dinapenia foi $17,2 \%$, sendo $16,6 \%$ nos homens e 17,7\% nas mulheres. Entre os indivíduos com 65 anos ou mais, a prevalência foi $28,2 \%$ (29,1\% nos homens e 27,5\% nas mulheres). A presença da dinapenia mostrou associação positiva com idade, velocidade de marcha reduzida, limitação autorrelatada em duas ou mais atividades básicas da vida diária, gênero, quedas, hospitalizações e doenças crônicas. A dinapenia mostrou associação negativa com escolaridade, atividade física e indice de massa corporal (sobrepeso/obesidade, $O R=0,26)$. Aproximadamente 9\% da dinapenia eram atribuíveis a riscos modificáveis. O estudo indica que a dinapenia é prevalente em brasileiros com 50 anos ou mais, e que medidas para melhorar a escolaridade e atividade física têm o maior potencial de reduzir a dinapenia nessa população.

Envelhecimento; Força da Mão; Desempenho

Físico Funcional; Força Muscular; Fatores

Socioeconômicos

\section{Resumen}

El objetivo del estudio fue evaluar la prevalencia de la dinapenia y factores asociados en una muestra nacional representativa de individuos con 50 años o más en Brasil. Se realizó un estudio transversal. El presente estudio usó datos de referencia del Estudio Longitudinal de Salud de Ancianos Brasileños (ELSI-Brasil por sus siglas en portugués). La variable dependiente era dinapenia, definida como baja fuerza muscular (<27kg para hombres $y<16 \mathrm{~kg}$ para mujeres). Se incluyeron como covariables en el modelo logístico las características sociodemográficas: estado de salud, comportamientos relacionados con la salud y desempeño físico. Se calcularon fracciones atribuibles poblacionales para los factores que demostrasen asociación significativa con el resultado. Se estudiaron a 8.386 participantes con 50 años o más (53,3\% del sexo femenino). La prevalencia de la dinapenia fue de un $17,2 \%$, siendo un $16,6 \%$ en hombres y un $17,7 \%$ en mujeres. Entre los individuos con 65 años o más, la prevalencia fue de 28,2\% (29,1\% en los hombres y 27,5\% en mujeres). La presencia de la dinapenia mostró asociación positiva con edad, velocidad de marcha reducida, limitación autoinformada en dos o más actividades básicas de la vida diaria, género, caídas, hospitalizaciones y enfermedades crónicas. La dinapenia mostró una asociación negativa con: escolaridad, actividad física $e$ indice de masa corporal (sobrepeso/obesidad, OR =0,26). Aproximadamente un 9\% de la dinapenia era atribuible a riesgos modificables. El estudio indica que la dinapenia es prevalente en brasileños con 50 años o más, y las medidas para mejorar la escolaridad y actividad física poseen un mayor potencial para reducir la dinapenia en esa población.

Envejecimiento; Fuerza de la Mano; Rendimiento Físico Funcional; Fuerza Muscular; Factores Socioeconómicos
Submitted on 06/Jun/2019

Final version resubmitted on 11/Oct/2019

Approved on 21/Oct/2019 